\title{
Aminosalicylate Calcium
}

National Cancer Institute

\section{Source}

National Cancer Institute. Aminosalicylate Calcium. NCI Thesaurus. Code C76468.

A calcium salt form of aminosalicylic acid, an analog of para-aminobenzoic acid (PABA)

with antitubercular activity. 